\title{
ORÍGENES DE LA REPRESENTACIÓN TOPOGRÁFICA DEL TERRENO EN ALGUNOS MAPAS HISPANOAMERICANOS DEL SIGLO XVI
}

\author{
Manuel Morato-Moreno \\ Departamento de Ingeniería Gráfica. Univerisdad de Sevilla \\ mmorato@us.es
}

\section{RESUMEN}

Los descubrimientos de los territorios americanos motivaron levantamientos planimétricos durante el siglo XVI, desarrollándose diversos métodos empíricos para la representación del terreno, así como su relieve. En este amplio corpus encontramos tres mapas en los que sorprende la forma de representar la orografía, apartándose de métodos pictóricos utilizados desde los orígenes de la cartografía hasta el siglo XVIII. El procedimiento empleado en estos mapas supone, en cierta medida, una anticipación intuitiva del método científico que utiliza la topografía moderna, que representa en una vista ortogonal el relieve mediante las curvas de nivel, y que no será desarrollado hasta dos siglos más tarde.

Palabras clave: historia de la cartografía, representación del relieve, Hispanoamérica, siglo XVI.

\section{ABSTRACT}

Because of the discovery of the new American territories, many topographic surveys were performed during the sixteenth century. These maps developed various empirical methods to represent terrain and relief. In this comprehensive corpus, we find three maps with surprising representations of terrain that depart from pictorial methods, that were used from the origins of cartography until the eighteenth century. The procedure used on these maps is, to a certain

Fecha de recepción: marzo 2015.

Fecha de aceptación: marzo 2016. 
extent, an intuitive anticipation of the scientific method used by modern surveying, in which the land relief is represented in an orthogonal view by the contour lines. This method was not developed until two hundred years.

Keywords: History of Cartography, representation of relief, South America, sixteenth century.

\section{INTRODUCCIÓN. EVOLUCIÓN DE LA REPRESENTACIÓN DEL RELIEVE}

La representación del territorio desde sus orígenes hasta el Renacimiento ha seguido un proceso evolutivo, caracterizado por la permanente mutación, selección y pervivencia de los mejores ingenios gráficos, y el abandono de aquellos otros esquemas o recursos, menos flexibles, que presentaban menores posibilidades. A pesar de que dicho proceso se constata en la manera de representar la planimetría del terreno a través de los tiempos, en lo tocante a la representación de la altimetría, se puede concluir que hasta el siglo XVI y, excepto algunos casos puntuales, no se avanza más allá de la convención de los perfiles abatidos ${ }^{1}$, el sistema más antiguo utilizado a lo largo de los siglos. Casi desde sus orígenes se ha querido representar las montañas vistas desde el infinito, abatiéndolas sobre el plano horizontal, con el inconveniente de que esa proyección escondía una parte del mapa, que era, sin embargo, el principal objetivo. Se veían ríos interrumpidos por montañas y lugares que se escondían a la visión del espectador por lo que no se encontraban representados (León Casas, 2001). La simbología del perfil abatido, adoptando cualquiera de sus múltiples formas, por su sencillez se erigió durante mucho tiempo en la representación cartográfica por excelencia del relieve. Sin embargo, esta expresión no refleja la cota de las elevaciones, ni permite realizar comparaciones altimétricas, ni la gran superficie que abarcan las montañas, pudiéndose entender que esos rasgos simbolizan, de igual manera, el desconocimiento del elemento representado y la intencionalidad de expresar ese territorio desde la óptica de un obstáculo físico, formado por el almacenamiento de tierras y rocas que otros elementos naturales como el viento y el agua habrían provocado.

De forma resumida, los distintos modos de representar la altimetría fueron apareciendo a lo largo de la historia de la cartografía según el siguiente orden. Alzados o perfiles abatidos: fue muy utilizado desde los orígenes de la representación territorial (plano de Nuzi, 2500 a. C.), durante todo el Renacimiento y continuó utilizándose hasta el final del siglo XVIII. Perspectiva paralela utilizando un punto de vista elevado, vista panorámica o paisajista: comienza a utilizarse en el periodo renacentista, es una representación más realista de las formas del terreno que surge cuando los científicos y artistas empezaron a interesarse por la representación de la orografía del paisaje. Puntos acotados: utilizado fundamentalmente en los mapas marinos, se comienza a emplear a partir del siglo XVIII cuando las operaciones de altimetría permiten la determinación de un cierto número de cotas de altitud adaptadas a un nivel de referencia. Sombreado: aunque está técnica plástica ya se utilizó en algún caso aislado en el Renacimiento (mapas de Leonardo de Windsor y en los Códices de Madrid), es en el siglo

1 Perfil abatido: dícese de la representación cartográfica del relieve consistente en la plasmación de las montañas mediante el trazado de su perfil abatido sobre el plano horizontal. 
XVIII donde se emplea de forma generalizada. A estas técnicas siguieron posteriormente otras: líneas estructurales, líneas de máxima pendiente, curvas de configuración horizontal, normales, tintas hipsométricas,..., para concluir en el método de las líneas de nivel (mapa con curvas de profundidad de N. S. Cruquius, 1730), origen próximo del Sistema de Planos Acotados².

En los primitivos mapas babilonios ya aparecen montañas en perfil abatido, como el de Ga Sur, igual procedimiento emplearon los egipcios en los mapas y planos que se han conservado y los romanos en obras más tardías, como los itinerarios del estilo de la Tábula de Peutinger. Este sistema continuó usándose hasta fechas muy recientes: fue el empleado en los portulanos del siglo XV. Los únicos progresos realizados, con el transcurso de los siglos, habían sido exclusivamente de tipo estético o pictórico, intentando dar sensación de profundidad y relieve. Hasta ese momento la representación del relieve del terreno plantea uno de los problemas cartográficos más difíciles de resolver, puesto que se trataba de plasmar un fenómeno de tres dimensiones, cuyas variaciones cuantitativas son continuas, en una superficie plana (Wood, 1992). El fenómeno existe y tiene un valor bien determinado en cualquier punto y, salvo en áreas muy pequeñas, se considera como algo excepcional que la superficie del suelo pueda ser asimilada a cualquier superficie matemática. En la evolución de la representación del territorio, la planimetría consiguió aproximarse en lo esencial a la realidad representada, con ejemplos de sorprendente exactitud como el de los portulanos, en los que a pesar de la precisión en el trazado de las costas, la representación de la orografía en las tierras del interior estuvo estancada durante mucho tiempo por la insuficiencia de métodos, técnicas de levantamiento e instrumentos de medida; sin olvidar la falta de interés por detallar la topografía de los interiores continentales en una cartografía cuyo fin fundamental fue la ayuda a la navegación.

El impulso humanista del periodo renacentista demandó mapas con más detalle y a mayor escala, y el interés por las características del medio natural comenzó a despertar. Además, una representación más realista de las formas terrestres iba a aparecer en los mapas cuando científicos y artistas empezaron a interesarse por las montañas. Los primeros y más bellos ejemplos de este desarrollo son los mapas de la Toscana dibujados por Leonardo da Vinci entre 1502 y 1503 . Por primera vez se muestran las formas de relieve en grafías individuales pero relacionadas de forma continua, como si se viesen en perspectiva oblicua o a vista de pájaro (Imhof, 1982). Estos mapas presentes tanto en el manuscrito de Windsor como en los

2 Los signos convencionales para la representación bidimensional de las montañas comienzan a desarrollarse desde sus inicios en las primeras civilizaciones babilónicas (hacia 3800 A.C.), y su historia se ha resumido con frecuencia. Para Lynam abarca un periodo aproximado que va desde el año 1250 hasta el siglo XIX, señalando que los cambios esenciales implican un desplazamiento gradual de la vista en alzado o perfil abatido, hacia la vista oblicua o de pájaro, para llegar a la representación en planta (Lynam, 1953; Wood, 1992). Este cambio de perspectiva se vio acompañado por el desarrollo del sombreado convencionalizado, desde las prácticas arbitrarias medievales en las perspectivas a vista de pájaro, hasta el sombreado sobre las representaciones en planta. A principios del siglo XVIII, los cartógrafos comenzaron a dibujar las montañas aplicando rayados, efecto plástico que simulaba la sombra provocada en las colinas por una supuesta iluminación desde arriba. Esto dio lugar, en opinión de Skelton, al desarrollo de las normales -hachures-, líneas dibujadas en la dirección de la pendiente, indicándose la magnitud de la misma por el espesor de las líneas y el intervalo entre ellas. (Skelton, 1958, Wood, 1992). Esta convención se utilizó con efectos plásticos en 1757 en los mapas físicos de Philippe Buache. Aunque Buache ya había utilizado curvas de nivel veinte años antes (Plano del Canal de la Mancha y de parte del Mar del Norte de 1737). Sin embargo, tuvo que transcurrir gran parte del siglo XIX para que las curvas de nivel, una convención aún más abstracta que las normales, estableciesen su capacidad superior para representar el relieve terrestre. Pero no fue hasta mediados del siglo XIX que las curvas de nivel desplazaron al método de las normales en la representación del relieve en muchos de los grandes levantamientos nacionales. 
Códices de Madrid alcanzan una notable calidad gráfica y expresan además una preocupación por la representación del territorio que surgía de la nueva sociedad renacentista (Gentil, 1998). Leonardo dividió la región de la Toscana y parte de Umbría en 22 zonas para su representación en otros tantos mapas (figura 1). En estos mapas, Leonardo introduce una nueva forma de representación que hace posible percibir las diferencias de altitud en el paisaje. Este método nunca había sido aplicado previamente en cartografía y constituye el arquetipo de la manera de representar la altitud a través del color (Cantile, 2003).

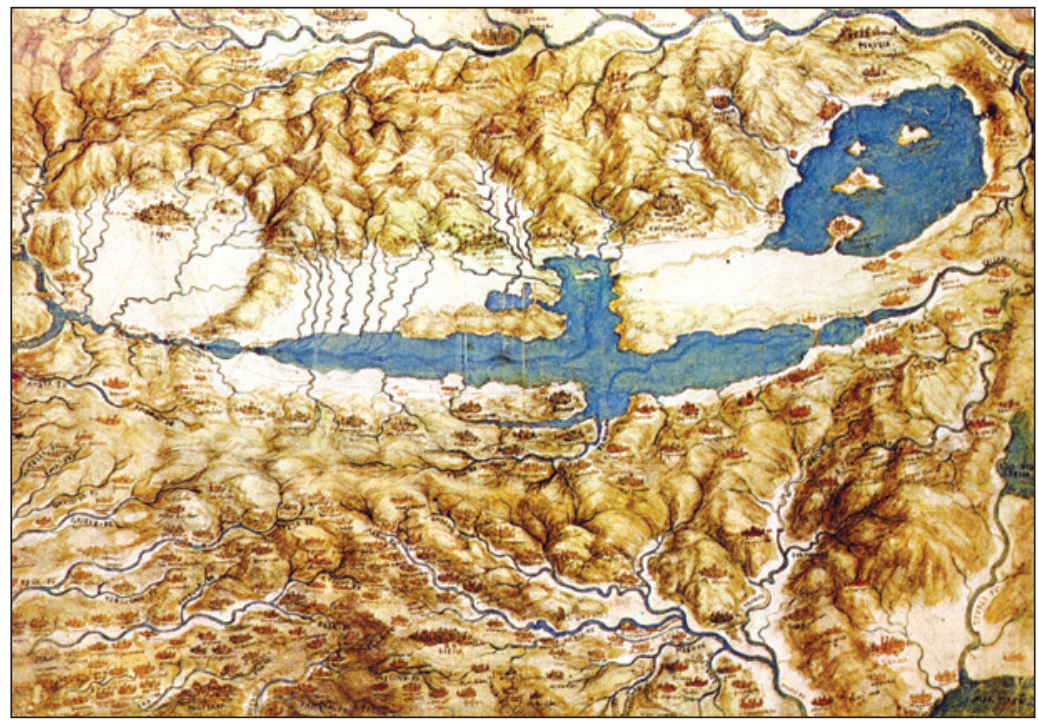

Fuente: The Royal Library at Windsor. Londres, Reino Unido.

Aunque no se puede hablar en absoluto de Topografía antes del inicio del siglo XVII, arquitectos y pintores se habían esforzado hasta entonces en subrayar los principales rasgos físicos del terreno. La historia de la pintura y del dibujo nos ofrece magníficos ejemplos de estas representaciones donde al margen de sus propios valores artísticos, aparecen algunos aspectos esenciales del territorio, en lo que a la orografía se refiere. En el Renacimiento la representación de los elementos naturales por parte de los pintores sufre un alto proceso de codificación que tiende a encasillarlos en esquemas fácilmente reproducibles y controlables. En un intento de codificar los elementos naturales, el artista geometriza y manipula las formas al objeto de hacer más fácil su uso (Báez, 1993).

\section{OBJETIVOS, CONCEPTUALIZACIÓN Y METODOLOGÍA}

El principal objetivo de este artículo es poner de manifiesto que los documentos cartográficos estudiados pueden suponer, en cierta medida, una anticipación empírica o intuitiva 
de los métodos topográficos modernos utilizados para la representación del relieve terrestre, que se desarrollaron doscientos años más tarde de que estos mapas fuesen trazados. En el contexto post-Harley, ${ }^{3}$ nuestro enfoque no se basa en una historia social, filosófica ni ideológica del mapa. El propio Harley escribió "Mi lectura del mapa no es técnica (ésta cuenta ya con bastante literatura), sino política" (Harley y Laxton, 2005). La producción cartográfica actual tiene como premisa proporcionar una imagen precisa de la superficie terrestre. Pero esto no ha de significar que el estudio de los mapas antiguos se centre en la comparación de dichos documentos cartográficos con las representaciones contemporáneas, en cuanto a precisión topográfica, conformidad y convenciones se refiere. Sin desmerecer en absoluto opciones metodológicas basadas en aspectos culturales, políticos o sociales, no creemos justo tachar de positivista, en el sentido peyorativo del término, a los estudios que tratan de buscar en el mapa antiguo vestigios de prácticas cartográficas que con el tiempo se han incorporado a la cartografía llamada científica, pues la Historia también es comprender el presente a la luz del pasado. Nuestro enfoque ha tratado de estudiar los documentos cartográficos analizados también como expresión de los conocimientos geográficos de una época determinada.

En cuanto a la metodología utilizada, ésta parte de una primera fase de localización de los documentos cartográficos de interés para el objetivo propuesto. Para el análisis de cada imagen, se parte de un breve estudio histórico de la misma, ubicándola en el contexto espacio-temporal. La regla básica del método histórico es que solo se pueden interpretar los documentos en su contexto. Esta norma se aplica igualmente a los mapas, que deben llevarse de regreso al pasado y situarse estrictamente en su propio periodo y lugar (Harley y Laxton, 2005). Se asume ahora que es imperioso reinsertar la imagen en su tiempo, en su geografía y en su sociedad. Esto ha tenido el meritorio efecto de reencauzar un problema metodológico de larga duración: el análisis cartográfico solía reducirse a una descripción superficial en la que el mapa se pensaba como un objeto tan singular que no parecía resistir el diálogo con otros objetos o imágenes de su época (Mendoza y Lois, 2009). En cualquier estudio iconográfico, sólo a través del contexto se puede descubrir adecuadamente el significado y la importancia del objeto de análisis. Tales contextos pueden ser definidos como las circunstancias en que se hicieron y usaron los mapas (Harley y Laxton, 2005).

En un segundo momento se procedió al análisis individualizado de cada documento gráfico, atendiendo tanto a sus características físicas como a sus contenidos. Gracias a las modernas técnicas de digitalización en alta resolución, hemos podido efectuar un minucioso examen de cada documento cartográfico, analizando detalles que difícilmente podrían apreciarse trabajando con el documento original. Se ha realizado una labor de redibujado de cada mapa, atendiendo a diferentes niveles de estudio: accidentes geográficos, hidrografía, relieve, asentamientos y poblaciones, vegetación, red de caminos, toponimia, etc. Esto también nos ha permitido analizar y comparar la información subyacente en el mapa abstrayéndola de la imagen pictórica en la que se encuentra inmersa.

3 Harley, John Brian (1932-1991), geógrafo, historiador y experto en historia de los mapas, famoso por sus exploraciones de las relaciones entre ideología, cartografía, conocimiento y poder. El proyecto de Harley sobre la historia de la cartografía estaba íntimamente ligado a otros desarrollos en la teoría social, y en particular con la naturaleza de la producción de conocimiento y de sus conexiones con los contextos sociales de su producción. 


\section{ANTECEDENTES DE LAS CURVAS DE NIVEL}

La representación científica de la altimetría del terreno se considera que comienza con el descubrimiento de las curvas de nivel. Los antecedentes de la representación del relieve mediante curvas de nivel no surgieron para describir la orografía, sino para representar lechos hidrográficos. Por tanto, los precursores de las curvas de nivel aparecieron cronológicamente antes en el campo de la batimetría que en el de la topografía. La representación más temprana de isóbatas descubierta hasta ahora se encuentra en un mapa manuscrito, fechado 1584, del agrimensor holandés Pieter Bruinsz. Este mapa, bastante sorprendente para la época, muestra una línea de profundidad a 7 pies en el lecho del río Spaarne, cerca de Haarlem. ${ }^{4}$ El mapa (figura 2) representa una sección del Spaarne, río canalizado ubicado en el norte de Holanda, que conecta el canal de Ringvaart con el Mar del Norte. Este documento se considera la primera representación batimétrica porque contiene una línea punteada que conecta puntos de igual profundidad (Fockema y van t'Hoff, 1947).

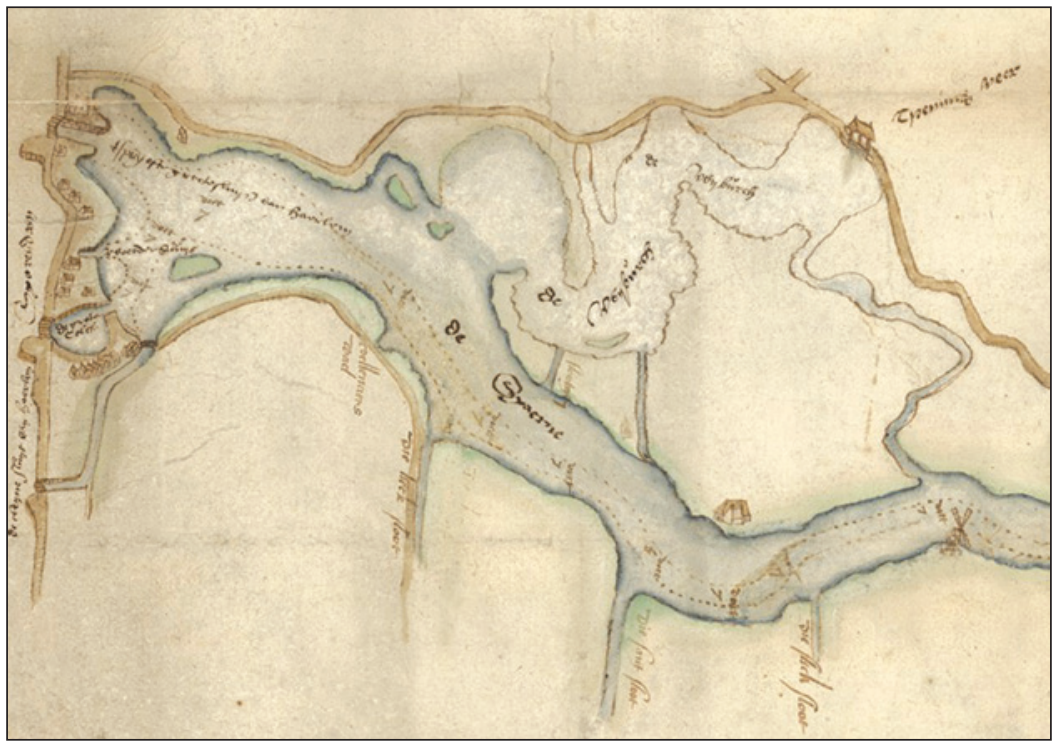

Fuente: Biblioteca de la Universidad de Utrecht.

Siglo y medio más tarde, en 1730, otro holandés Nicolaus Samuelis Cruquius (16781754) representó el lecho del estuario del Merwede, en la confluencia de los ríos Mosa y Waal. Si bien en el dibujo de Bruinsz se traza una única línea punteada uniendo puntos de una

4 Más tarde, en Rotterdam en 1697, se levantaron mapas isobáticos manuscritos realizados por Pierre Ancelin mostrando el río Mosa con contornos de profundidad 5 a 5 pies. Intentos similares fueron seguidos en Francia y en Holanda. En 1725, Luigi de Marsigli publicó su Histoire Physique de la Mer (Historia Física del Mar), y adjuntó a este trabajo una Carte du Golfe du Lion, que tuvo líneas de profundidad (Imhof, 1982). 
misma profundidad, en este mapa (figura 3) aparece ya todo un sistema de líneas isóbatas a diferentes profundidades, con indicación numérica de las mismas, presentando separaciones menores en las cercanías de las márgenes del lecho y de las islas fluviales. Posteriormente el método fue desarrollado por el ingeniero francés Philippe Bouache (1700-1773) a partir del año 1738, quien trazó un mapa del Canal de La Mancha aprovechando prácticas anteriores para medir los fondos marinos utilizadas por los navegantes, mediante sondas que medían las diferencias de cotas por debajo del nivel del agua, limitándose a unir con una línea los puntos obtenidos con igual medida (Gentil, 1998). Estos antecedentes corresponden a la representación planimétrica de lechos hidráulicos. En 1771, Du Carla crea el primer mapa con curvas de nivel de una isla imaginaria. Finalmente, en 1791, Dupain-Triel compiló el primer mapa con curvas de nivel de una porción de tierra existente, la de Francia (Imhof, 1982).

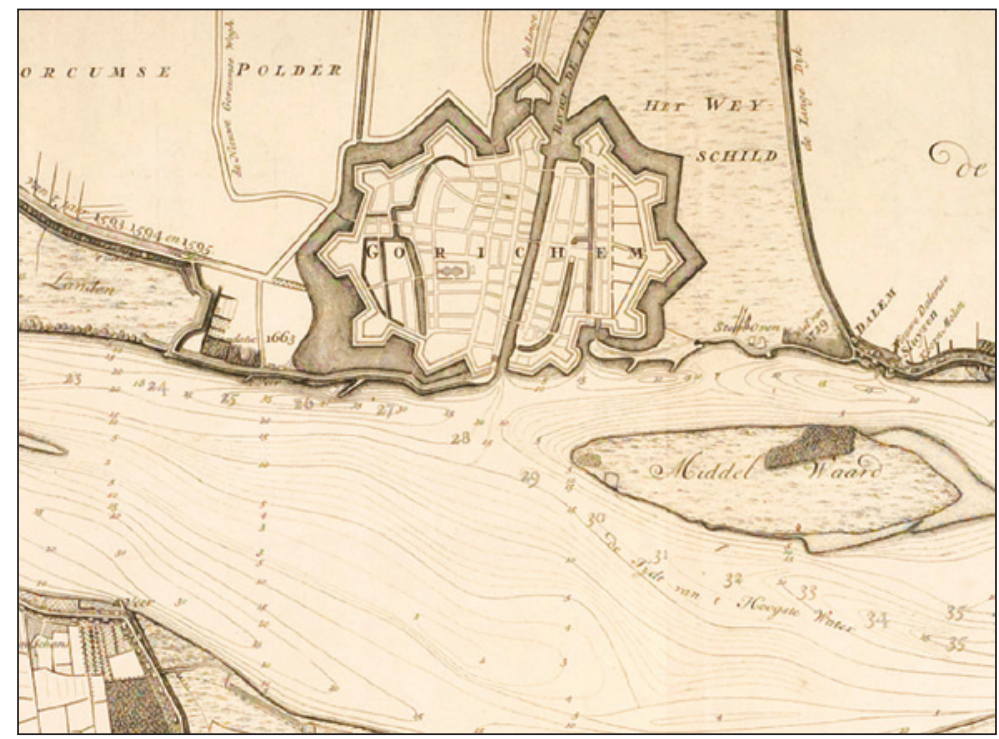

Fuente: Biblioteca de la Universidad de Delft.

Es comúnmente aceptada la tesis de que la representación en una sola vista en planta del relieve terrestre no se produce hasta finales del siglo XVIII. Sin embargo existen mapas manuscritos en la cartografía producida a raíz del descubrimiento y colonización de América, donde se constata que se utilizaron métodos empíricos para la representación plana de la orografía, que al igual que los trabajos de Leonardo en la Toscana, pueden ser considerados antecedentes de los métodos topográficos modernos, en lo que respecta a un sistema gráfico para poder representar en el plano el relieve de la superficie de la Tierra. Estos documentos son, por orden cronológico: la traza del capitán Diego Palomino, de 1549; el mapa de la Relación Geográfica de Huehuetlán, de 1579 y el mapa de la Relación Geográfica de San Miguel y San Felipe de los Chichimecas, fechado en 1580. 


\section{TRAZA DE LA CONQUISTA DEL CAPITÁN DIEGO PALOMINO, 1549}

Diego Palomino nació en Jaén en 1506. Marchó a América siguiendo a Pizarro en la decisiva expedición de 1531-32 (Molina, 1992). Tomó parte en la fundación de diversas poblaciones del virreinato del Perú en la región del oriente amazónico, se hizo encomendero y participó en diversas expediciones de conquista de aquel territorio. A mediados del siglo XVI se promovieron expediciones de conquista y de población en los confines del virreinato del Perú, adentrándose en zonas todavía inexploradas en la región selvática del norte peruano colindante con Quito. En el año de 1549 y como consecuencia de unas de sus expediciones, Diego Palomino realiza una relación de las provincias que había en el Chuquimayo (actual Chinchipe), ubicada en la parte noroccidental del Perú, a la que adjuntó un mapa de las tierras conquistadas (Jiménez, 1885).

El llamado mapa de Palomino fue descubierto en 1885 por Marcos Jiménez de la Espada (1831-1898), quien lo publicó sin reparar en su valor para la historia de la representación planimétrica del relieve. Muy probablemente, Jiménez de la Espada copió el mapa original y reprodujo el dibujo así obtenido (figura 4), que es la imagen que se ha conocido y difundido desde entonces del documento. Veinticinco años después de su hallazgo, el geógrafo Antonio Blázquez y Delgado-Aguilera (1859-1950) publicó un detallado estudio del mapa donde resaltó su importancia para la historia de la cartografía y concretamente en lo que a la representación planimétrica del relieve se refiere; considerando que podría ser un anticipo de las curvas de nivel, adelantándose casi tres siglos a su utilización y sistematización (Blázquez, 1910). Este documento gráfico reviste gran interés pues representa una de las primeras aproximaciones cartográficas de la región, siendo además de las escasas representaciones territoriales que nos han llegado de esa época, correspondiente a una zona fuera de Centroamérica. Al igual que Jiménez de la Espada, Blázquez reprodujo en su estudio el dibujo copia del mapa original, que se ha difundido hasta nuestros días, llegando a afirmar que el procedimiento empleado por Diego Palomino "precede en más de dos siglos a los de los cartógrafos del siglo XIX” (Blázquez, 1910). En su opinión el mapa del conquistador jiennense inicia ya el trazado del relieve mediante curvas de nivel (Blázquez, 1910).

El texto de la relación, que hizo el capitán Diego Palomino por orden de Pedro de la Gasca, se encuentra en la Biblioteca de la Real Academia de la Historia en Madrid, con el título "Relación de la provincia de Chuquimayo, hecha por el capitán Diego Palomino en 1549 por orden del Presidente de la Real Audiencia de la Ciudad de los Reyes, Pedro Gasca", en un legajo que contiene tres folios manuscritos en el recto y verso. El mapa original (figura 5), prácticamente inédito, se conserva también en la Real Academia de la Historia, en el Departamento de Cartografía y Artes Gráficas. En su descripción bibliográfica consta: "Título al verso: Traça de la conquista del Capitán Diego Palomino, 44 x 61,5 cm. Manuscrito dibujado sobre tinta azul y negra, y sepia (en dos casas junto a la Imagen de la luna). Relieve por sombreado en lápiz gris, papel verjurado" (Manso, 2012). A pesar de su deterioro parcial, puede comprobarse la fidelidad de la copia. El documento ha sido restaurado recientemente debido al avanzado deterioro del papel como consecuencia de los dos pliegues que se practicaron en las mitades horizontal y vertical del mapa (ver la figura 7). 
Figura 4

TRAZA DE LA CONQUISTA DEL CAPITÁN DIEGO PALOMINO. DIBUJO COPIA DEL ORIGINAL ¿MARCOS JIMÉNEZ DE LA ESPADA?

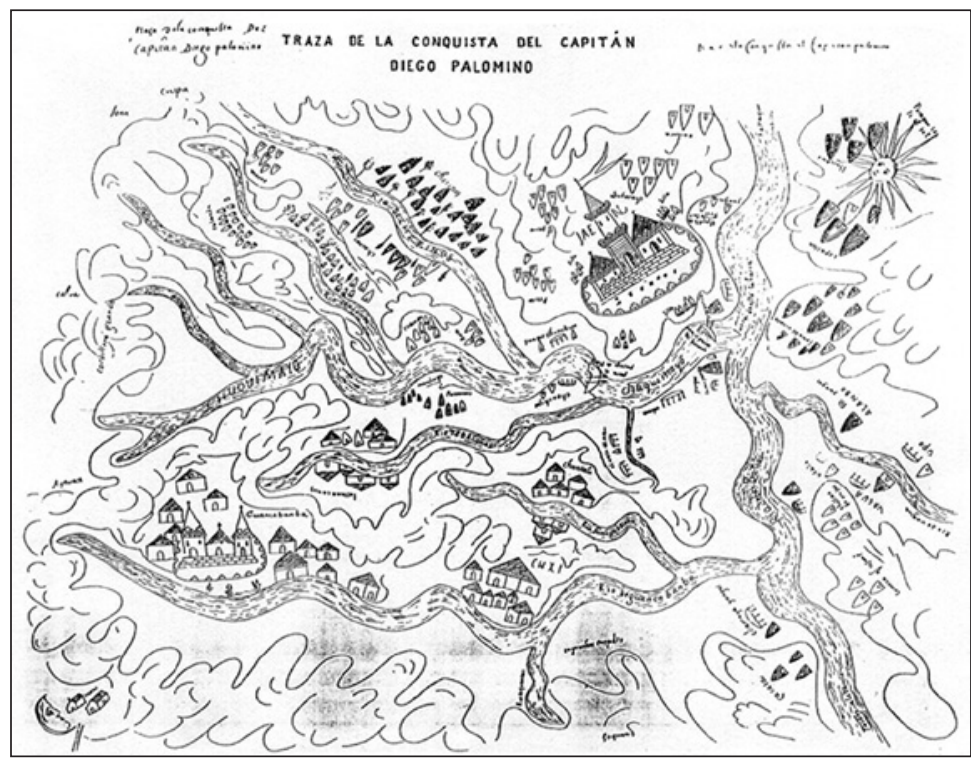

Fuente: A. Blázquez: Una joya cartográfica americana del siglo XVI, 1910.

Figura 5

TRAZA DE LA CONQUISTA DEL CAPITÁN DIEGO PALOMINO. DIEGO PALOMINO, 1549

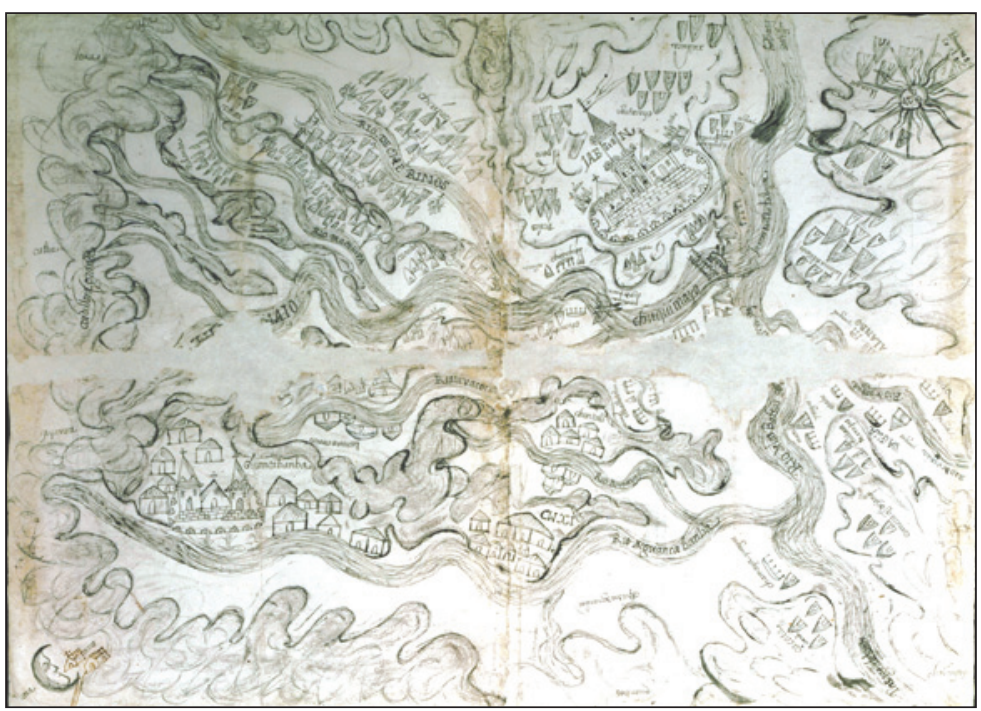

Fuente: Real Academia de la Historia, Madrid. 


\section{IV.1. Estudio gráfico del mapa}

El mapa, que representa con aceptable exactitud la hidrografía de la comarca descubierta por su autor, presenta una ejecución suelta. Tiene una rara orientación pues la dirección esteoeste coincide con una de las diagonales del dibujo, señalada con las figuras antropomorfas de un sol en la esquina superior derecha y una luna en la esquina opuesta. La población de Jaén, que Palomino fundó y bautizó en honor de su patria chica, se alinea con los puntos cardinales. Tanto los pueblos, aldeas y poblados de indios, como la escasa vegetación representada; se presentan en alzado abatido. Jaén y Guancabanba, las dos poblaciones más importantes de la región se significan de forma diferente al resto. Mientras que para los pueblos y aldeas se utiliza el alzado abatido de sencillas casas, cabañas o chozas, Jaén y Guancabanba se representan por la planta de un recinto amurallado con forma ovalada, en cuyo interior se dibujan los alzados abatidos de edificios con torres rematadas por cubiertas piramidales, teniendo la de Jaén tres cuerpos con chapitel. Para representar las poblaciones el autor del mapa parece haber utilizado un croquis de cada pueblo en lugar de un signo o convención, como sucede en multitud de ejemplos en la cartografía de la época, en donde funcionan signos metonímicos como: iglesia = pueblo de españoles, cabaña = poblado de indios .

Para representar la orografía (figura 6.1) Palomino utiliza una convención consistente en líneas sinuosas, generalmente abiertas, que rodean la red hidrográfica y las poblaciones. Se distinguen unas curvas principales y otras auxiliares, cuyo trazo es más suelto, fino y tenue. No encontramos ningún signo sobre la representación del relieve mediante perfiles abatidos, la convención más habitual utilizada en la cartografía desde sus orígenes. Las curvas se van alejando, cada vez más, de las márgenes de los ríos en el sentido de la corriente del agua y, por último, las que ocupan las partes altas de las montañas tienen configuración de línea cerrada, a diferencia de las que se encuentran más bajas, junto a los ríos, que poseen, formando las sinuosidades especificadas, formas abiertas y grandes longitudes. En algunas zonas ha trazado líneas auxiliares, en forma de curvas abiertas, sin duda para hacer más patente el escalonamiento del terreno (Blázquez, 1910).

Estas líneas sinuosas se asemejan a las curvas de configuración horizontal, ${ }^{5}$ precedente de las curvas de nivel, que estarían disponibles un cuarto de milenio después (Silva, 2005). Hay que reconocer que el procedimiento ideado por Palomino no goza de uniformidad, ya que los edificios, chozas, barcas, plantas, etc., se dibujan abatidos, en distintas direcciones, sobre el plano horizontal de proyección. El Capitán se ha guiado, según el modo antiguo de las aldeas, no por un signo convencional, sino por el croquis del lugar (Valcárcel, 1940). Llama la atención la práctica ausencia de caminos terrestres, quizás porque en esta región las comunicaciones se realizaban fundamentalmente por vía fluvial. A diferencia de la mayoría de los mapas elaborados durante la conquista y colonización, con participación indígena en mayor o menor grado, en los que sobreviven algunas de las características que tenían los de manufactura prehispánica; en este mapa no se detecta la presencia de ningún elemento de la cartografía autóctona. A continuación se transcriben las leyendas e inscripciones (tabla 1) contenidas en el mapa (figura 7). Se ha respetado la escritura original, indicándose entre paréntesis en su caso, la ortografía actual de los ríos y topónimos que han pervivido.

5 El método de las "curvas de configuración horizontal", a medio camino entre el sistema de líneas de máxima pendiente, ideado a finales del siglo XVIII, y el de las curvas de nivel verdaderas; se dio a conocer a raíz de su utilización por Francisco Coello (1822-1898) (Reguera, 1998). 
Figura 6

TRAZA DE LA CONQUISTA DEL CAPITÁN DIEGO PALOMINO, RE-DIBUJADO

1: OROGRAFÍA. 2: HIDROGRAFÍA. 3: POBLACIONES. 4: MAPA COMPLETO

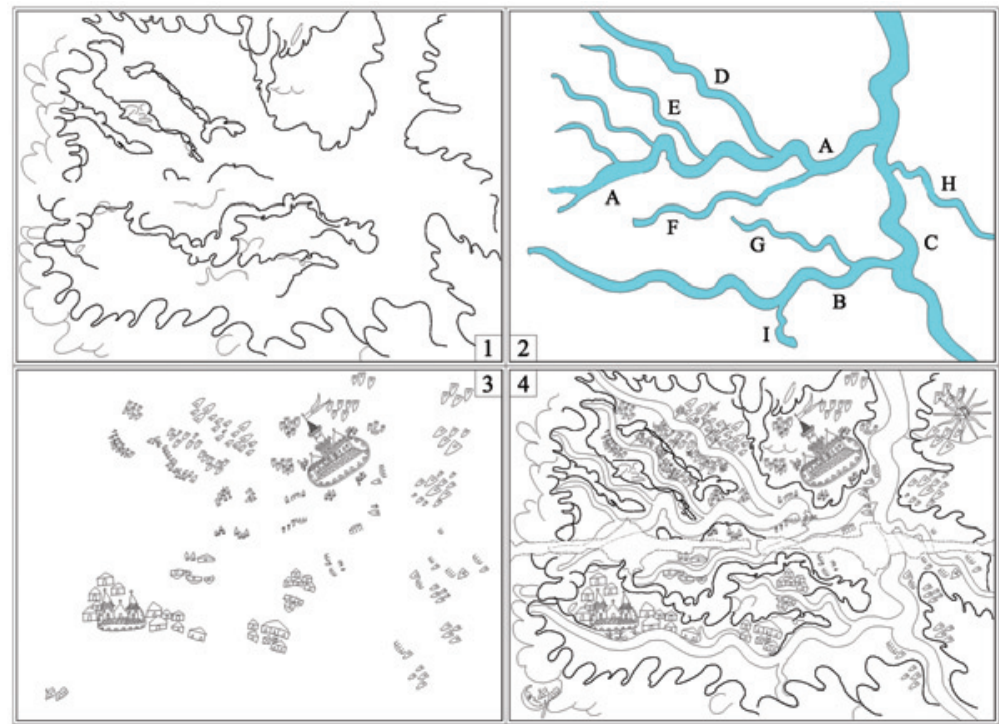

Fuente: elaboración propia.

Figura 7

TRAZA DE LA CONQUISTA DEL CAPITÁN DIEGO PALOMINO, RE-DIBUJADO

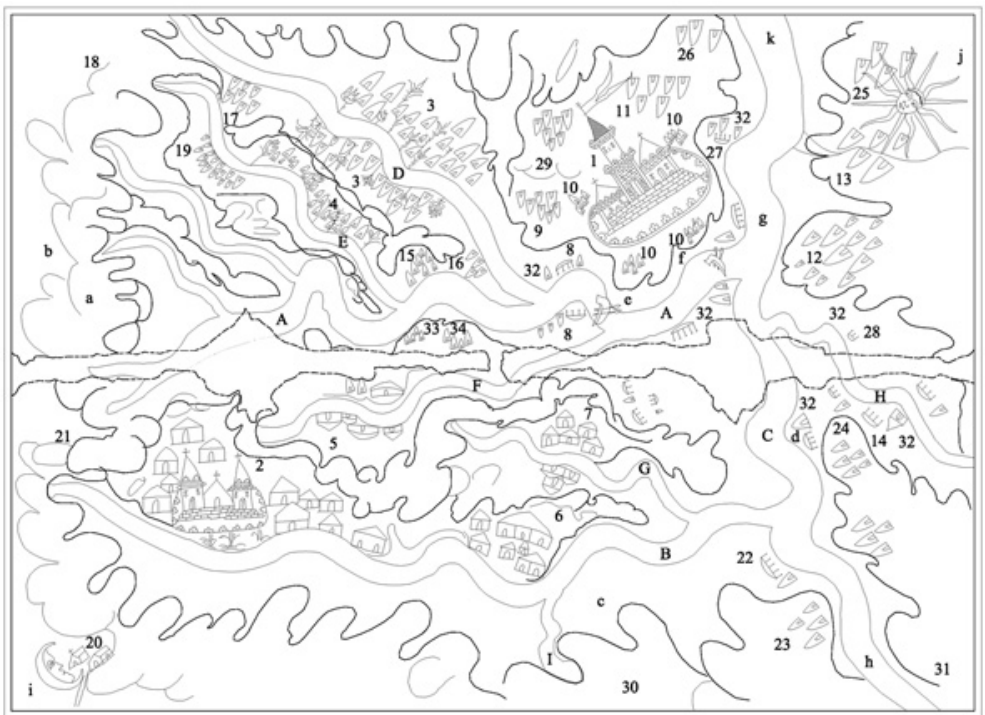

Fuente: elaboración propia. 


\begin{tabular}{|c|l|}
\cline { 2 - 2 } \multicolumn{1}{c|}{} & Red hidrográfica: \\
\hline A & Río Chuquimayo \\
\hline B & Río Guancabanba (Huancabamba) \\
\hline C & Río de las Balsas (Río Marañón) \\
\hline D & Río de Cherinos (Chirinos) \\
\hline E & Río de Aconipa \\
\hline F & Río Tavacona (Tabaconas) \\
\hline G & Río de Mayobanba (Mayobamba) \\
\hline H & Río de Bagua \\
\hline I & Río de Guanbos (Huambos) \\
\hline
\end{tabular}

\begin{tabular}{|l|l|}
\hline 20 & Caxas \\
\hline 21 & Ayavaca (Ayabaca) \\
\hline 22 & Chamaya \\
\hline 23 & Cacata \\
\hline 24 & Chillaos de Roxas \\
\hline 25 & Lanque \\
\hline 26 & Xulluca (Julluca) \\
\hline 27 & El pueblo de la sal \\
\hline 28 & Alanbo (Alambo) \\
\hline 29 & El Paco (¿El Parco?) \\
\hline 30 & Guanbos (Huambos) \\
\hline 31 & Chachapoyas \\
\hline
\end{tabular}

\begin{tabular}{|c|l|}
\cline { 2 - 3 } \multicolumn{1}{c|}{} & Topónimos: \\
\hline 1 & Jaen (Jaén) \\
\hline 2 & Guancabanba (Huancabamba) \\
\hline 3 & Cherinos \\
\hline 4 & Tavancaras (Tabancaras) \\
\hline 5 & Tavaconas (Tabaconas) \\
\hline 6 & CWXI (¿Cuxibamba?) \\
\hline 7 & Chontalí (Chontali) \\
\hline 8 & Chenchipe \\
\hline 9 & Perico \\
\hline 10 & Silla \\
\hline 11 & Chacaynga (Chacainga) \\
\hline 12 & La loma del viento \\
\hline 13 & Copallan (Copallán) \\
\hline 14 & VAGWA (Bagua) \\
\hline 15 & Coanda \\
\hline 16 & Anta \\
\hline 17 & Xaroca (Xoroca) \\
\hline 18 & Loxa (Loja) \\
\hline 19 & Palanda \\
\hline
\end{tabular}

\begin{tabular}{|l|l|}
\cline { 2 - 2 } \multicolumn{1}{c|}{} & Indios: \\
\hline 32 & Yungas \\
\hline 33 & Mandingas \\
\hline 34 & Pucaraes \\
\hline
\end{tabular}

\begin{tabular}{|c|l|}
\cline { 2 - 3 } \multicolumn{1}{c|}{} & Otras leyendas: \\
\hline a & cordillera grande (cordillera del Cóndor) \\
\hline b & calva \\
\hline c & espalda de guanbos (Huambos) \\
\hline d & mocache \\
\hline e & para el pasaje de Piura \\
\hline f & para el pasaje de Levante \\
\hline g & juntas do está la barca \\
\hline h & pasaje a levante \\
\hline i & luna \\
\hline j & por aquí sale el sol \\
\hline k & hasta aquí se ha visto \\
\hline
\end{tabular}

Fuente: elaboración propia.

\section{LAS RELACIONES GEOGRÁFICAS DE INDIAS}

La necesidad de conocer y representar con precisión los nuevos territorios ultramarinos bajo el imperativo de su control y delimitación, así como lograr un mayor conocimiento de la disponibilidad de los recursos que ofrecían, llevó a que en el año 1577, por Real Cédula 
de Felipe II, se enviase a América un cuestionario para ser contestado por los funcionarios de la administración indiana, alcaldes mayores y corregidores. ${ }^{6}$ El objetivo de esta encuesta de 50 preguntas era conocer más sobre los territorios de ultramar, un intento de configurar cada vez mejor la imagen interior del continente. Las respuestas, conocidas como Relaciones Geográficas de Indias, constituyen el mayor cuerpo de fuentes originales de la América española para el siglo XVI.

Aunque el mapa que levantó Diego Palomino en 1549 fue el primero que encontramos en el ámbito americano con esta forma característica de representar en proyección horizontal el relieve del terreno, en el transcurso de nuestra investigación, en la que revisamos las distintas representaciones del territorio en Hispanoamérica durante el siglo XVI, aparecieron otros dos mapas que utilizaban una convención similar a la del mapa de Palomino para representar la orografía. Estos documentos pertenecen a las "pinturas" que acompañaron al corpus de las Relaciones Geográficas de Indias: el mapa de Huehuetlán, fechado en 1579 y el de San Miguel y San Felipe de 1580, ambos de autor desconocido. Si bien ambos mapas han sido tratados por distintos investigadores de las Relaciones Geográficas de Indias, ${ }^{7}$ ninguno de los estudios hasta ahora publicados se ha enfocado hacia la representación del relieve del terreno que en ellos se realiza, ni los ha relacionado entre sí, ni con el de Diego Palomino.

\section{MAPA DE LA RELACIÓN GEOGRÁFICA DE HUEHUETLÁN, 1579}

La Relación Geográfica de Huehuetlán se realizó en 1579 por Francisco Nájera, presbítero-vicario, aunque la redacción, como era preceptivo, corrió a cargo del escribano, Pedro de Illescas (Echenique, 1992), interviniendo monjes agustinos en la conducción de la encuesta (Morales, 2001). En el texto de la Relación de Huehuetlan se explica el origen del nombre de esta localidad, cuyo significado es "lugar de viejos, o de los ancianos", porque en el sitio se quedaron unos viejos que iban de paso (Fagetti, 1998). Comprende el pueblo de Santo Domingo Huehuetlán (actualmente perteneciente al estado mexicano de Puebla) y los de su jurisdicción o sujetos. Santo Domingo Huehuetlán se encuentra en un enclave surcado por un riachuelo de aguas cristalinas del mismo nombre, afluente del Atoyac. En el texto de la Relación Geográfica de Quatlatlauca y Huehuetlán, (Acuña, 1985) se dice que el descubridor de estos pueblos fue Hernán Cortés, quien mandó gobernarlos a Juan de Santa Clara y a Villamartín, respectivamente (Fagetti, 1998). Parece ser que Huehuetlán era sede de un convento dominico (Acuña, 1985), como se sabe gracias a la Relaciones Geográficas, y todavía hoy existen varios en la región: Tecali, Tepeaca, Cuauhtinchan y Tecamachalco (Fagetti, 1998).

6 El cuestionario fue publicado como Real Cédula en San Lorenzo del Escorial el 25 de mayo de 1577 con el título de Cédula, instrucción y memoria para la formación de las Relaciones y descripciones de los pueblos de Indias.

7 Entre los estudios que se han publicado sobre las pinturas que acompañaron a las Relaciones Geográficas de Indias, y que incluyen al mapa de Huehuetlán o al de San Miguel y San Felipe, podemos citar los de Acuña, 1985; Morales, 2001 y Mundy, 1996. 


\section{VI.1. Estudio gráfico del mapa}

La pintura (figura 8) describe la región donde se asienta el pueblo de Santo Domingo Huehuetlán y todos los que le estaban sujetos. El autor trazó la red hidrográfica, en color marrón oscuro, constituida por un río principal (de nombre también Huehuetlán), así como por sus afluentes y numerosos arroyos que los alimentan; en un entorno de relieve bastante accidentado y naturaleza frondosa. Se sabe que las inscripciones o leyendas en español que posee este mapa fueron añadidas por un indígena noble, don Juan Hernández (Mundy, 1996). En ellas se indican los nombres de los pueblos sujetos y describe la topografía de la región. Ésta corresponde a un territorio montañoso debido a su localización junto a la Sierra del Tentzo, que forma parte de la Sierra Madre Oriental, y su relieve viene determinado por la presencia de los cordones serranos meridionales del eje neo volcánico. Pueden identificarse en las leyendas los nombres de los 18 pueblos sujetos a la jurisdicción de Huehuetlán: San Miguel, San Juan, Santa Marta, Santa María Magdalena y San Agustín, entre otros. Aunque no existe ninguna indicación gráfica o escrita sobre la orientación del mapa, por la situación de los pueblos, puede deducirse que está orientado al norte. Según el texto de la Relación, en la comarca había una cantera de yeso y era abundante la piedra de cal, utilizada en la construcción de edificios. En el mapa se representa en dos lugares una acumulación de rocas en forma de montículo, que probablemente se corresponda a la situación de sendas canteras (figura 10). Una está junto al pueblo de San Agustín y la otra en las cercanías de Santa Ana. Este último pueblo es conocido como Santa Ana Tanlaxa, nombre con el que se rotula en el mapa. La palabra híbrida Tanlaxa está formada por el locativo tan (o tam), que en lengua tének quiere decir "lugar de" (Grosser, 1991), y la palabra "laja", que en español significa "piedra que forma capas".

El pueblo de Huehuetlán se representa en la pintura de la Relación (figura 8) por el dibujo de la sencilla iglesia de su convento dominico. Situada en la parte central izquierda, se dibuja con su alzado abatido junto a la planta del atrio -dibujada con doble línea marcando el espesor del muro- ambos en color rojo. Es una construcción de un solo cuerpo, entrada con arco de medio punto y campanario. Una red de caminos en color rojo conecta esta iglesia cabecera con las parroquias subsidiarias, representadas por un dibujo idéntico al de la iglesia dominica, pero de menor tamaño y con tinta negra, con su correspondiente toponimia en español y, en algunos casos, con comentarios en náhuatl. Los signos para los poblados se muestran de manera proporcional al rango de los lugares en cuestión (Harley, 2005). La representación de los caminos presenta aquí ciertas peculiaridades, pues se trazan con una única línea, en color rojo y, en aquellos que parecen caminos principales, con mayor grosor, se incluyen huellas de pisadas en color negro, una convención característica de la cartografía indígena.

Esta vista geográfica propone la comprensión genérica de la topografía circundante de las poblaciones especificadas en los textos, y viene a responder a la representación del espacio territorial donde se introducen las cabeceras y las estancias dependientes de las mismas. Para ello se utilizan elementos esquemáticos que estructuran el conjunto como caminos, ríos, montañas, y construcciones que, metonímicamente, vienen a identificar los distintos enclaves urbanos (López, 2007). En este mapa son iglesias y su tamaño está acorde con su 
importancia jurídica. ${ }^{8}$ A veces la jerarquía se especifica con el aumento de detalles o elementos, como se evidencia en el dibujo del campanario de la iglesia conventual y el de las iglesias subsidiarias. Este modelo de representación de las comunidades con asentamientos nucleados, siguiendo una jerarquía entre la cabecera y sus sujetos, se encuentra en muchos de los mapas -pinturas- que acompañaron a las Relaciones Geográficas.

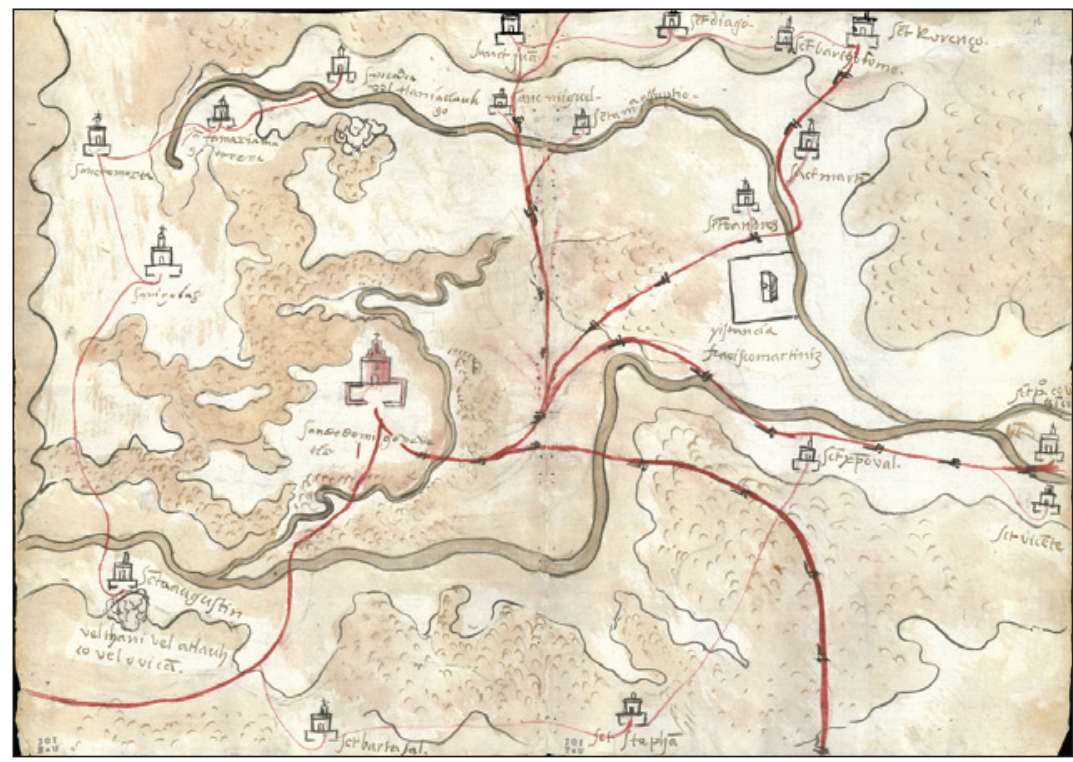

Fuente: BLAC, Benson Latin America Collection, Universidad de Texas, Austin.

Para representar la orografía se han trazado unas líneas sinuosas que circundan los cauces de los ríos y las inflexiones del terreno. En algunos casos estas curvas se cierran dentro de los límites del mapa, creándose áreas que se colorean con distintos tonos marrones que, podrían diferenciar las tierras más altas de las bajas, o las de escasa vegetación de las boscosas (ambas hipótesis no son incompatibles). De cualquier manera, el terreno se muestra en consonancia con las últimas técnicas europeas (Buisseret, 1998). Este sistema de líneas abiertas y cerradas establece una zonificación del territorio: unas áreas están coloreadas en marrón claro y las otras con el mismo color más oscuro, estando además estas últimas rellenas con un grafismo que recuerda en cierto modo a las escamas, toperas o los montículos agrupados utilizados en cartografía para representar las montañas desde los tiempos más remotos. Al igual que ya hiciera Leonardo, la innovación de este artista fue usar distintos tonos de color para denotar cambios de elevación. A continuación se transcriben las leyendas e inscripciones (tabla 2) contenidas en el mapa (figura 10).

8 Sobre el valor de estas representaciones centradas por iglesias, véase MUNDY, 1996. 
Figura 9

MAPA DE LA RELACIÓN GEOGRÁFICA DE HUEHUETLÁN, RE-DIBUJADO.

1: OROGRAFÍA. 2: HIDROGRAFÍA. 3: CAMINOS Y POBLACIONES. 4: MAPA COMPLETO

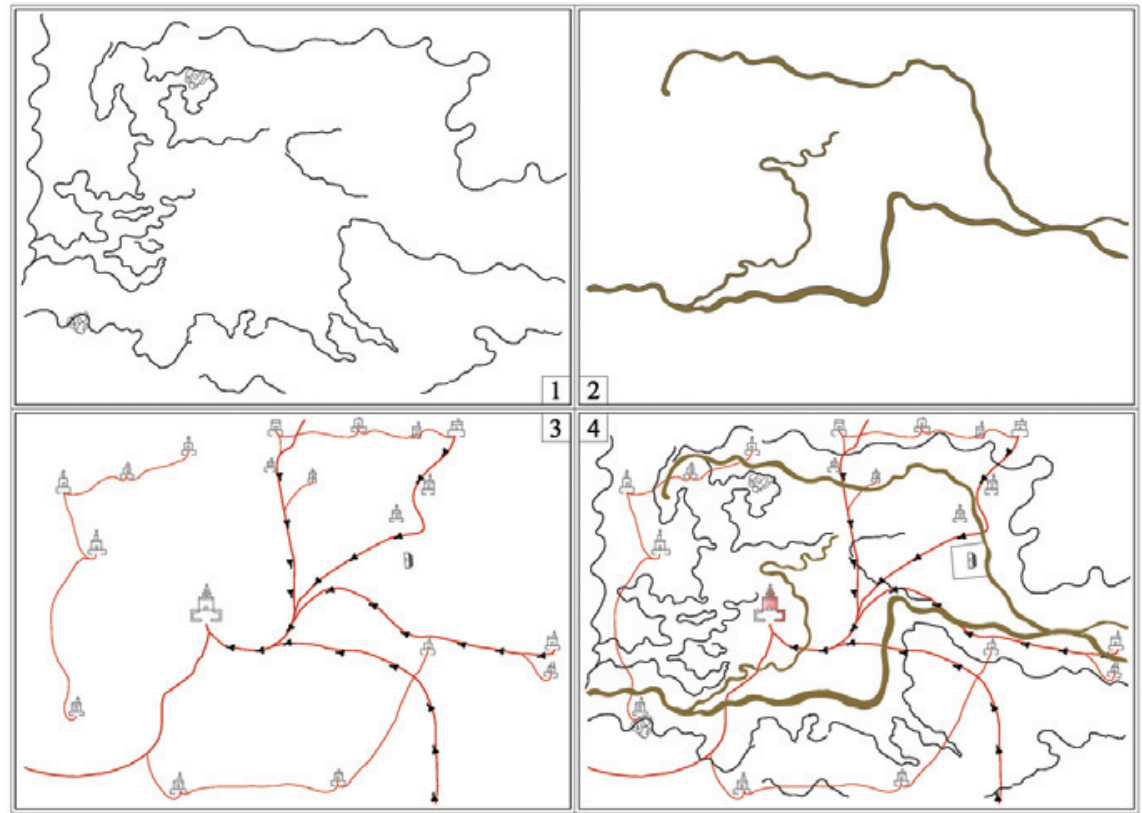

Fuente: elaboración propia.

Tabla 2

LEYENDAS DEL MAPA DE HUEHUETLÁN

\begin{tabular}{|c|l|}
\cline { 2 - 2 } \multicolumn{1}{c|}{} & Topónimos: \\
\hline 1 & Santo Domingo Huehuetlán \\
\hline 2 & San Agustín \\
\hline 3 & San Nicolás \\
\hline 4 & Santa Marta \\
\hline 5 & Santa María Magdalena \\
\hline 6 & Santa Ana Tanlaxa \\
\hline 7 & San Miguel \\
\hline 8 & San Juan \\
\hline 9 & Santa María Asunción \\
\hline 10 & Santiago \\
\hline 11 & San Bartolomé \\
\hline
\end{tabular}

\begin{tabular}{|r|l|}
\hline 12 & San Lorenzo \\
\hline 13 & San Martín \\
\hline 14 & San Andrés \\
\hline 15 & San Cristóbal \\
\hline 16 & San Vicente \\
\hline 17 & San Pedro Coatzinco \\
\hline 18 & San Esteban \\
\hline 19 & Santa Bárbara \\
\hline
\end{tabular}

Fuente: elaboración propia. 


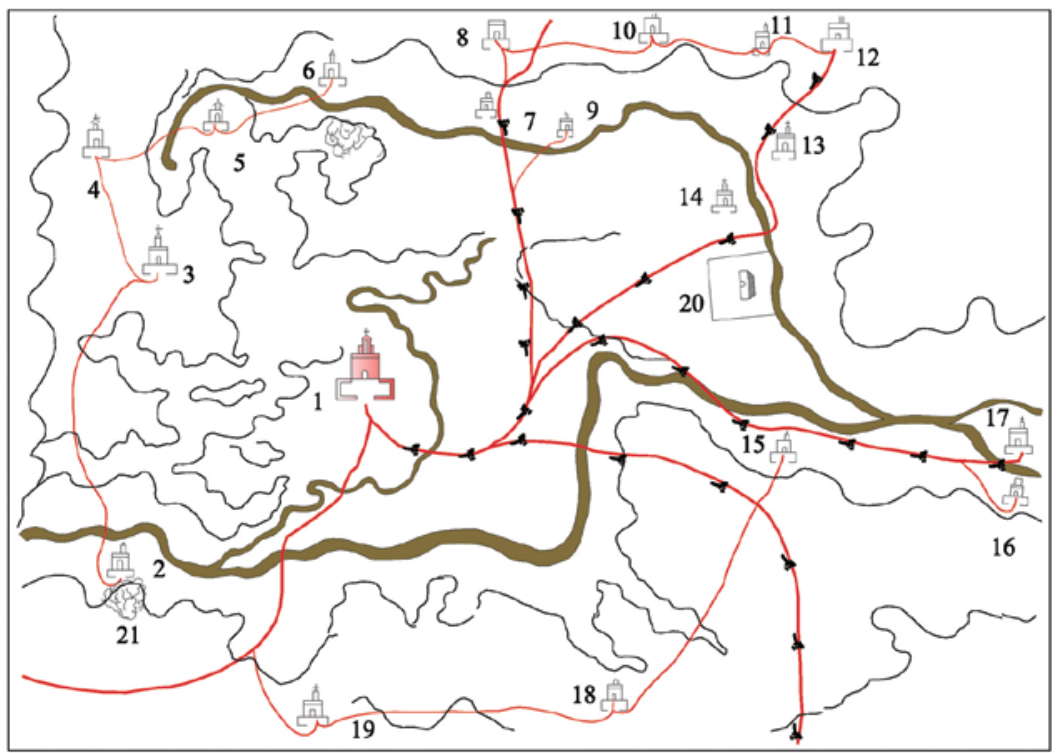

Fuente: elaboración propia.

\section{MAPA DE LA RELACIÓN GEOGRÁFICA DE SAN MIGUEL Y SAN FELIPE, 1580}

En la región septentrional de Nueva España, en una zona fronteriza de lo que los españoles llamaron la Gran Chichimeca, se encuentra Guanajuato, importante centro minero durante la Colonia, que en el siglo XVI estaba en su mayor parte bajo el control del imperio mexica. Esta región estaba habitada tanto por grupos nómadas, los hostiles y aguerridos indios chichimecas, como por grupos de agricultores sedentarios. Para llegar a Zacatecas, otra importante zona minera al norte de Guanajuato metida tierra adentro e igualmente en zona Chichimeca, hubo necesidad de fundar en 1544, en la época del virrey Luis de Velasco, los presidios de San Miguel de los Chichimecas o el Grande y San Felipe, que más tarde serían las villas del mismo nombre. En esta época se construyó un camino que conectaba la Ciudad de México con la de Zacatecas. Este camino constituía una arteria principal para el transporte de los preciados minerales hasta la capital de Nueva España, para ser llevados desde allí hasta la metrópoli. Este camino, conocido como Ruta de la Plata o Camino Real de Tierra Adentro, pasaba a través de los pueblos de San Miguel el Grande (actualmente San Miguel de Allende) y San Felipe (conocida por el mote de Torres Mochas debido a que la torre de su iglesia parroquial, finalizada en 1641, quedó inconclusa de acuerdo con los planos originales, hasta que se terminó en 1844). En 1580 se debió redactar la Relación Geográfica de San Miguel y San Felipe cuyo texto se encuentra perdido, pero de la que se conserva la pintura en el Archivo de la Biblioteca de la Real Academia de la Historia en Madrid (Acuña, 1985). 


\section{VII.1. Estudio gráfico del mapa}

La pintura (figura 11) muestra la geografía del valle del río San Miguel (río Laja), desde sus fuentes hasta San Francisco Chamacuero, así como la realidad de esta zona conflictiva, limítrofe con los indios chichimecas (Manso, 2012). Se representa con profusión de color, la orografía en tonos verdes y marrones, los ríos, arroyos y manantiales en color azul, las villas de San Miguel, San Felipe y el pueblo de San Francisco Chamacuero, las estancias del campo, los caminos, trazados con una sola línea roja, con sus ventas y los fuertes que los defendían, así como a los indios nómadas, cazando ganado y a los españoles que los combatían durante las guerras de conquista. A lo largo del camino se representan en alzado abatido en distintas direcciones, carros tirados por bueyes protegidos por soldados a pie y a caballo, armados con arcabuces. La cualidad fronteriza de la región y de enfrentamiento con los indígenas queda palpable en el dibujo de los mismos, armados con arcos y flechas, situados en las encrucijadas y lugares de posibles enfrentamiento (López, 2007).

\section{Figura 11}

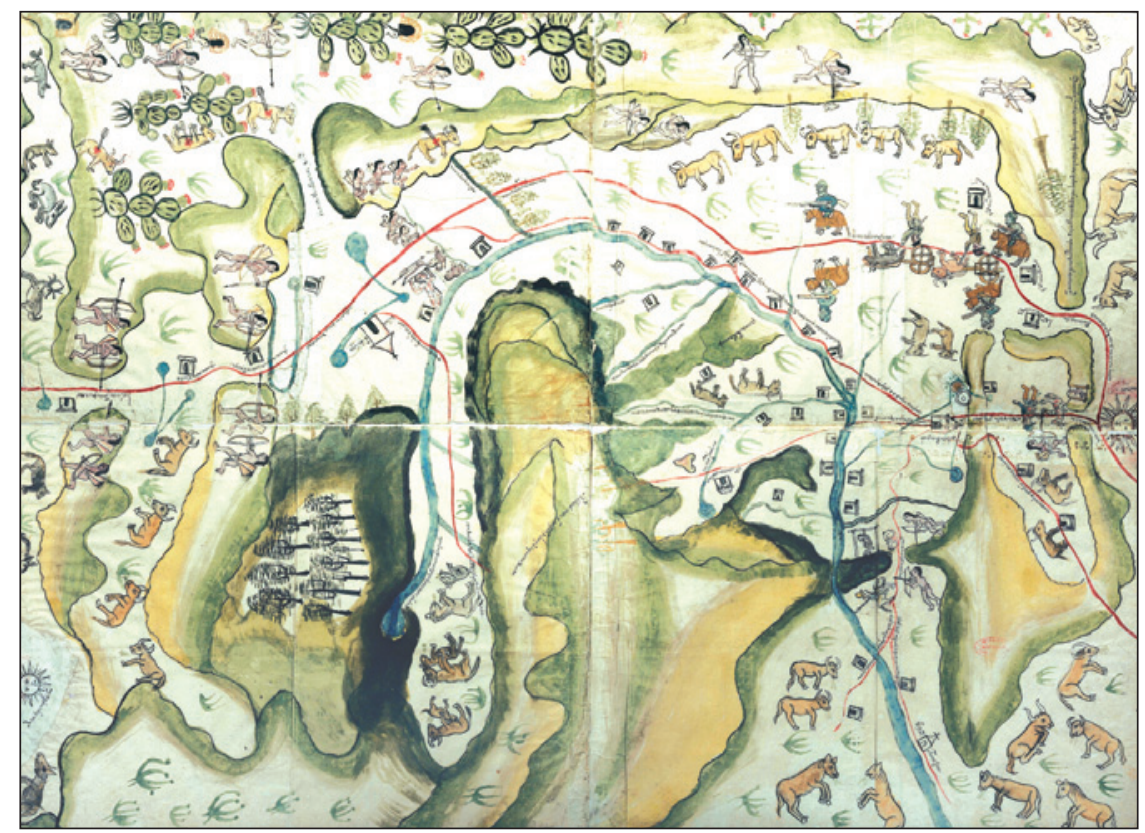

Fuente: RAH, Real Academia de la Historia, Madrid.

En los puertos de Nieto y Chamacuero encontramos sendos indios ajusticiados en la horca, y junto al segundo también se muestran las cabezas sangrantes de los frailes franciscanos decapitados que fueron asaltados por Chichimecas en el arroyo de Chamacuero, hoy Comonfort (Rea y Escandón, 1996) (figura 13.a). El hecho de estar el mapa orientado con 
sendas figuras de soles antropomorfos señalando el naciente y el poniente y de la ausencia de glifos y convenciones indígenas, sustenta la autoría española, aunque la técnica empleada es una mezcla entre los estilos europeo y nativo. Una característica genuinamente indígena del mapa es que además de representar accidentes geográficos, villas, estancias y caminos de la región, cuenta una historia.

La orografía de la zona es mayoritariamente plana, aunque atravesada por algunas serranías de mediana altitud en sus extremos este y oeste, así como en el centro del territorio. La principal corriente fluvial que atraviesa la región es el río Laja, cuyo nacimiento se representa en el mapa en la parte central izquierda (oeste) y que circunda la elevación que ocupa la parte central inferior del mismo: la serranía de Guanajuato; describiendo un meandro para desaparecer del mapa por el sureste. Este río continúa, fuera de la zona representada en el mapa, hacia el pueblo de Comonfort, a unos $25 \mathrm{Km}$ al sur de San Miguel; desembocando finalmente en el río Lerma. Además del río Laja, se representan otros arroyos menores, en uno de los cuales -el arroyo del Charco del Ingenio (parte central derecha del mapa)- se instaló el primer molino hidráulico o batán (figura 13.b) conocido que menciona la autorización virreinal, construido por los frailes y del que aún se conservan las ruinas.

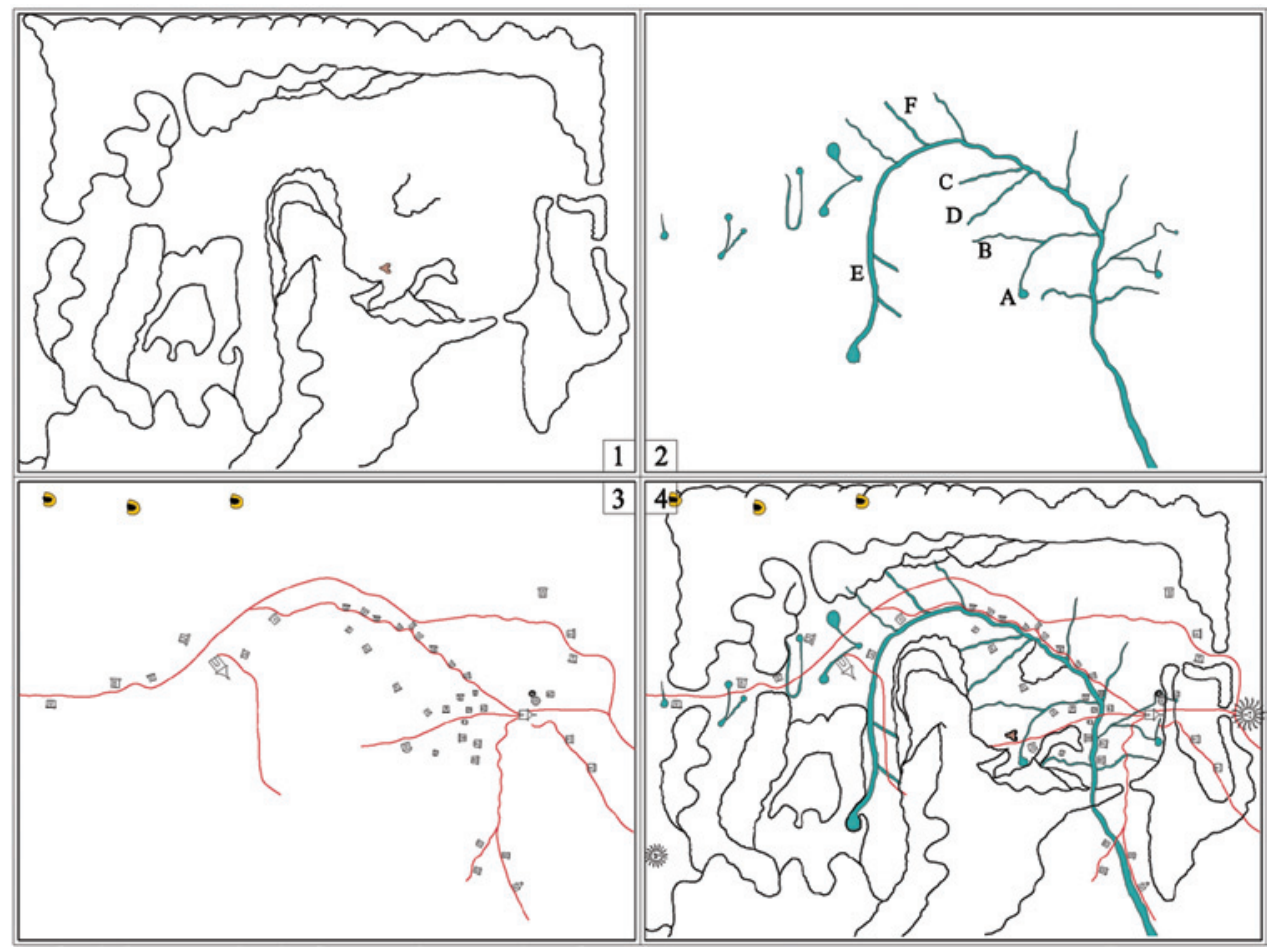

Fuente: elaboración propia. 
El terreno se representa por una serie de curvas (figura 12.1) que encierran áreas que son coloreadas en sus bordes y a veces también en el interior. Aunque en la parte superior del mapa estas curvas pueden parecer representar montañas en perfil abatido, en el resto del documento el trazado sinuoso de estas líneas, alternando partes cóncavas y convexas en todas direcciones, nos inclinan a descartar esta hipótesis. Esta convención queda reforzada por la utilización del color con degradados y sombreados para crear sensación de volumen. En la parte central del mapa, junto al pueblo de Santa Catalina y el río del mismo nombre, nos encontramos el dibujo de un tepetl, el símbolo -glifo- utilizado en la cartografía indígena para el cerro o la montaña (figura 13.c). Para la representación de los caminos se utiliza una línea de color rojo, mientras que para los ríos y arroyos se ha utilizado una doble línea, cuyo interior se rellena con color azul.

Las construcciones, vegetación, fauna y figuras humanas, se dibujan en alzado abatido. Los españoles con armaduras, armas de fuego y caballos con mantas, protegiendo los caminos y el ganado, mientras que los indios portan arcos y flechas (Morales, 2001). Tres convenciones son utilizadas para representar los lugares habitados (figura 13.d): para las villas de San Miguel, San Felipe y San Francisco, una sencilla iglesia o casa con esbelto tejado a dos aguas rematado por una cruz y puerta de entrada con arco de medio punto. Para las estancias de ganado y labranza se utiliza el alzado de una sencilla casa con cubierta plana, a veces con entrada con arco. Finalmente, los poblados de indios se representan por el dibujo de una cabaña realizada con material entretejido y forma semiesférica.

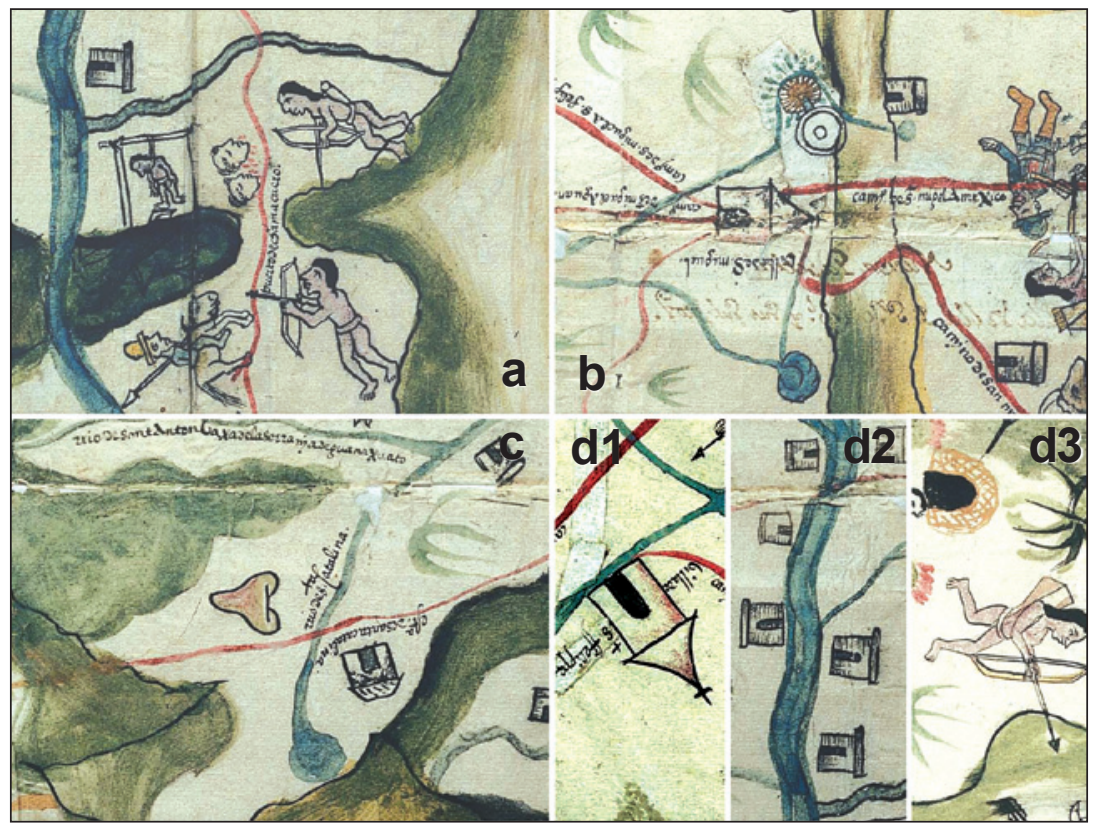

Fuente: Real Academia de la Historia, Madrid, y elaboración propia. 
Este mapa se ha relacionado por diversos autores con otro anterior a las Relaciones Geográficas denominado mapa de Nueva Galicia, conservado en el Archivo General de Indias (AGI, MP-México, 560) fechado en 1550. Como en los mapas prehispánicos, se ven en estos mapas escenas de combate en los que participan diversos grupos chichimecas, escenas que registran aconteceres al modo de los mapas-escenarios. Puede hoy contemplarse en estos mapas no poco de la realidad cultural: espacio, tiempo y actores, españoles e indígenas (León Portilla, 2005). A continuación se transcriben las leyendas e inscripciones (tabla 3) contenidas en el mapa (figura 14).

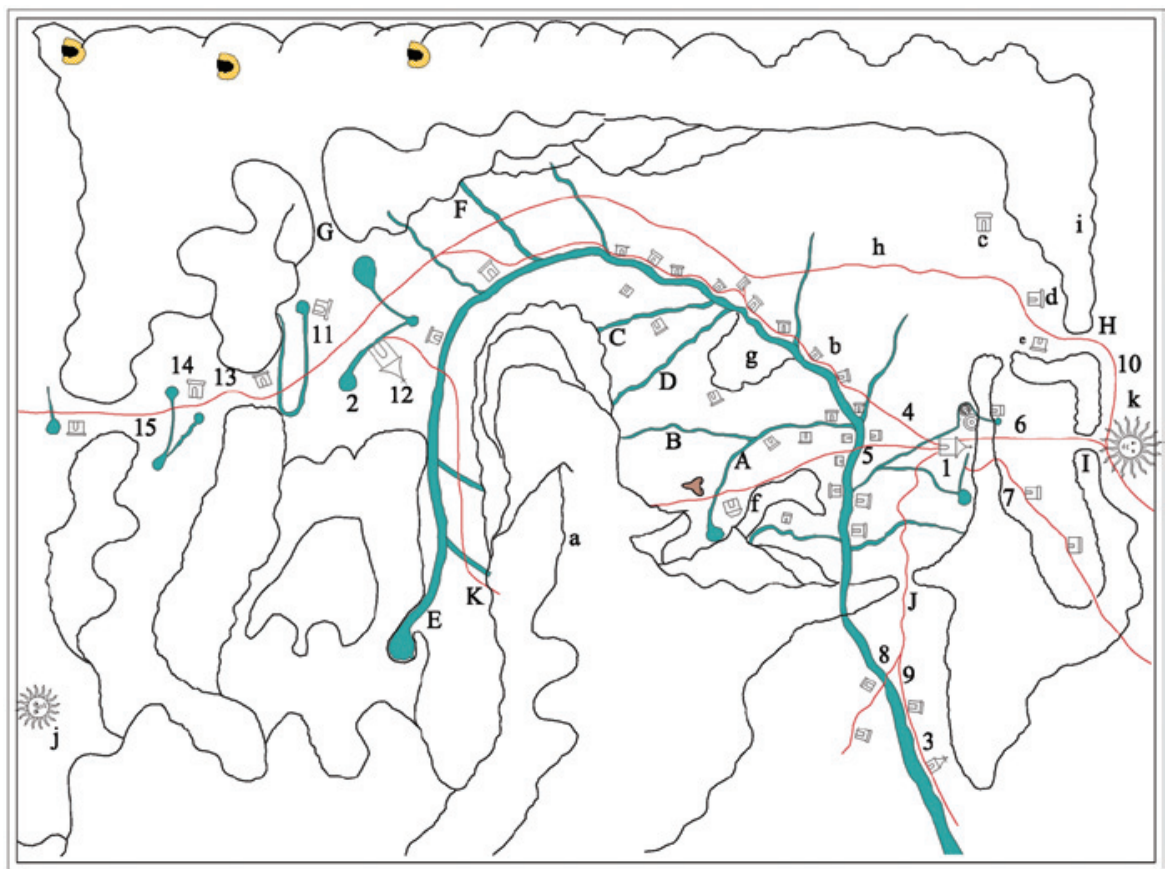

Fuente: elaboración propia.

\begin{tabular}{|c|l|}
\cline { 2 - 2 } \multicolumn{1}{c|}{} & Red hidrográfica: \\
\hline A & Río de Santa Catalina \\
\hline B & $\begin{array}{l}\text { Río de San Antón baja de la serranía de } \\
\text { Guanajuato }\end{array}$ \\
\hline C & Río del Gallinero \\
\hline
\end{tabular}

\begin{tabular}{|c|l|}
\cline { 2 - 2 } \multicolumn{1}{c|}{} & Orografía: \\
\hline G & Entrada al valle de San Francisco \\
\hline H & Puerto de Jofre \\
\hline I & Portezuelo de Nieto \\
\hline J & Puerto de Chamacuero \\
\hline
\end{tabular}




\begin{tabular}{|c|l|}
\hline D & $\begin{array}{l}\text { Río seco baja de la serranía de } \\
\text { Guanajuato }\end{array}$ \\
\hline E & $\begin{array}{l}\text { Nacimiento de este río que se llama de } \\
\text { San Miguel (Río Laja) }\end{array}$ \\
\hline 1 & Topónimos: \\
\hline 2 & Villa de San Miguel \\
\hline 2 & Villa de San Felipe \\
\hline 3 & San Francisco Chamacuero \\
\hline
\end{tabular}

\begin{tabular}{|c|l|}
\hline K & Este valle se llama el potrero de Xassco \\
\hline F & Río de los sauces \\
\hline 13 & Fuertes: \\
\hline 14 & Fuerte del portezuelo de San Felipe \\
\hline 15 & Fuerte de los Ojuelos \\
\hline
\end{tabular}

\begin{tabular}{|c|l|}
\cline { 2 - 3 } \multicolumn{1}{l|}{} & Caminos: \\
\hline 4 & $\begin{array}{l}\text { Camino de San Miguel a San Felipe y } \\
\text { Zacatecas }\end{array}$ \\
\hline 5 & Camino de San Miguel a Guanajuato \\
\hline 6 & Camino de San Miguel a México \\
\hline 7 & Camino de San Miguel a Querétaro \\
\hline 8 & $\begin{array}{l}\text { Camino de San Miguel a Celaya y } \\
\text { Michoacán }\end{array}$ \\
\hline 9 & $\begin{array}{l}\text { Camino de San Miguel a Chamacuero } \\
\text { y Apaseo }\end{array}$ \\
\hline 10 & Camino de México a Zacatecas \\
\hline 11 & Camino por San Felipe a Zacatecas \\
\hline 12 & Camino de San Felipe a Guanajuato \\
\hline
\end{tabular}

\begin{tabular}{|c|l|}
\cline { 2 - 3 } \multicolumn{1}{c|}{} & Otras leyendas: \\
\hline a & $\begin{array}{l}\text { Robledal entre San Miguel y } \\
\text { Guanajuato }\end{array}$ \\
\hline b & $\begin{array}{l}\text { Todas las casas que son ribera de este } \\
\text { río son estancias de vacas y algunas } \\
\text { labranzas }\end{array}$ \\
\hline c & Estancia de San Sebastián \\
\hline d & Estancia de los llanos \\
\hline e & Estancia de Villaseca \\
\hline f & Ermita de Santa Catalina \\
\hline g & Cerro de ¿Roldanejo? \\
\hline h & Llano de la ¿Mosina? \\
\hline i & $\begin{array}{l}\text { Caminando por este rumbo hacia el norte } \\
\text { se va por los pueblos de Sichú y Xalpatla } \\
\text { guaxteca y provincia de Panuco }\end{array}$ \\
\hline j & Aquí se pone el sol \\
\hline $\mathrm{k}$ & Oriente \\
\hline
\end{tabular}

Fuente: elaboración propia.

\section{CONCLUSIONES}

La delimitación de la forma tridimensional continua de la superficie terrestre siempre ha sido uno de los problemas más difíciles en cartografía. Desde los tiempos más remotos, las llamadas "escamas de pez", "montículos" o "panes de azúcar”, en perfil abatido o, en el mejor de los casos, en perspectiva oblicua, se han utilizado para representar el relieve (Thrower, 1996).

Aunque de distinta fecha, lugar y autoría, estos tres mapas realizados durante el siglo XVI y que representan distintas regiones hispanoamericanas; muestran la originalidad de representar el relieve del terreno con un método diferente a los habitualmente utilizados. No tratan de representar las montañas mediante su perfil abatido, ni en perspectiva oblicua de punto de vista elevado, o vista de pájaro; sino que de forma intuitiva parecen querer 
representar el relieve en una vista cenital. Para ello, y con algunas diferencias entre los tres mapas, el procedimiento utilizado consiste en representar el relieve mediante líneas sinuosas con inflexiones análogas a las del terreno, lo que implica un cierto conocimiento de su morfología y la capacidad para dibujarlas mediante sucesión de senos, alternando formas cóncavas y convexas. Nada que ver con el método, utilizado largamente en la historia de la cartografía, de los perfiles abatidos.

Lo interesante - lo asombroso- de estos tres mapas es que, al contrario de lo que hizo Leonardo en los mapas de la Toscana, no intentan representar el relieve por su apariencia real, cómo se vería el terreno en una fotografía aérea, sino que utilizan de manera intuitiva un sistema de líneas sinuosas vistas en planta que intentan constituirse en un signo convencional no pictórico para representar las características de la superficie terrestre. Por el contrario, en la representación de aquellos otros elementos que no forman parte del relieve, como los edificios, personas, árboles y plantas; en lugar de utilizar signos convencionales, se emplea el dibujo de su aspecto real, visto en alzado.

Esta manera intuitiva de plasmar en una sola proyección horizontal el relieve podría constituir un precedente empírico de lo que siglos más tarde se denominó "método de curvas de nivel aproximadas o figuradas", procedimiento que logra representar el terreno y su relieve en una sola proyección ortogonal y permite formarse una idea bastante aproximada a la realidad del relieve de la zona representada, aunque sin ninguna indicación numérica sobre altitudes o elevaciones. Evidentemente en el siglo XVI aún no se disponía de instrumentación adecuada para la nivelación de puntos en el terreno y su posterior trazado en el plano mediante curvas. En los mapas estudiados el relieve, representado por un sistema de curvas sinuosas, no se ha hecho siguiendo un criterio estrictamente técnico, sino más bien intuitivo.

Curiosamente en los tres casos se observa que el procedimiento para representar en proyección horizontal la orografía, coexiste con la representación en alzado utilizada para árboles, casas, chozas, así como las figuras de personas y animales; que se dibujan abatidas en distintas direcciones sobre el plano horizontal de proyección. En cuanto a la representación de los pueblos en estos tres documentos cartográficos, en el de Palomino se utiliza el croquis de la disposición de edificios, casas y cabañas; que no sabemos si corresponden a la imagen real que tuvieron esos lugares, pero que sin duda difiere en la forma en que se representan los asentamientos humanos en los otros dos mapas, mediante signos convencionales: una casa o una iglesia. En el primer caso la extensión de la ciudad, pueblo o aldea se indica por el número edificios, casas o cabañas; mientras que en el segundo es el tamaño del signo convencional el encargado de reflejar la importancia o extensión del lugar que representa.

\section{BIBLIOGRAFÍA}

ACUÑA SANDOVAL, R. (1985): Relaciones Geográficas del siglo XVI: Tlaxcala, vol. 5. México. Universidad Nacional Autónoma de México.

BÁEZ MEZQUITA, J.M. (1993): «Aspectos subjetivos de la representación del territorio en el dibujo y la pintura», EGA, Revista de Expresión Gráfica Arquitectónica, nº 1, 57-68. 
BLAZQUEZ Y DELGADO AGUILERA, A. (1910): Una joya cartográfica americana del siglo XVI. Madrid. Imprenta del Patronato de Huérfanos de Administración Militar.

BUISSERET, D. (1998): «Meso-American and Spanish Cartography» en The Mapping of the Entradas into the Greater Southwest (Reinhartz D. y Saxon G., eds.). Norman, University of Oklahoma Press, 30-55.

CANTILE, A. (2003): Leonardo genio e cartografo. La rappresentazione del territorio tra scienza e arte. Florencia. Instituto Geográfico Militar.

ECHENIQUE MARCH, F. I. (1992): Fuentes para el estudio de los pueblos de naturales de la Nueva España. México. Instituto Nacional de Antropología e Historia.

FOCKEMA, S. J. y VAN T'HOFF, B. (1947): Geschiedenis der Kartografie van Nederlands, La Haya. Martinus Nijhoff.

FAGETTI, A. (1998): Tentzonhuehue: el simbolismo del cuerpo y la naturaleza. México. Plaza y Valdés.

GENTIL BALDRICH, J. M. (1998): Método y aplicación de representación acotada y del terreno. Madrid. Bellisco.

GROSSER LERNER, E. (1991): Los tének de San Luis Potosí: lengua y contexto. Volumen 230 de Colección científica, Serie Lingüística. México. Instituto Nacional de Antropología e Historia.

HARLEY, J.B. y LAXTON, P. (Ed.) (2005): La nueva naturaleza de los mapas: Ensayos sobre la historia de la Cartografía. México. Fondo de Cultura Económica.

IMHOF, E. (1982): Cartographic Relief Presentation. Redlands. Esri Press.

JIMÉNEZ DE LA ESPADA, M. (1885): Relaciones geográficas de Indias, Perú. Madrid. Tipografía de Manuel G. Hernández.

LEÓN CASAS, M.A. (2001): El Sistema de Planos Acotados: historiografía de un convencionalismo gráfico y su aplicación en el ámbito de la Ingeniería Civil. Granada. Universidad de Granada.

LEÓN PORTILLA, M. (2005): «Cartografía prehispánica e hispano indígena de México», en Estudios de cultura Náhuatl, no 36, pp. 185-197.

LYNAM, E. (1953): The map Maker's Art. Londres. The Batchworth Press.

MANSO PORTO, C. (2012): Real Academia de la Historia. Selección de cartografía histórica (siglos XVI-XX). Madrid. Real Academia de la Historia.

MENDOZA VARGAS, H. y LOIS, C. (Eds.) (2009): Historias de la cartografía de Iberoamérica: Nuevos caminos, viejos problemas. México. Instituto de Geografía, UNAM.

MOLINA MARTÍNEZ, M. (1992): «La conquista de los Bracamoros y la fundación de Jaén por Diego Palomino», en Congreso de Historia del Descubrimiento (1492-1556): actas (ponencias y comunicaciones). Vol. 2. Madrid. Real Academia de la Historia, pp. 563-578.

MORALES FOLGUERA, J.M. (2001): La construcción de una utopía. El proyecto de Felipe II para Hispanoamérica. Málaga. Servicio de Publicaciones de la Universidad de Málaga.

MUNDY, B. E. (1996): The Mapping of New Spain: Indigenous Cartography and the Maps of the Relaciones Geograficas. Chicago. University of Chicago Press.

REA, A. y ESCANDÓN BOLAÑOS, P. (Ed.) (1996): Crónica de la orden de N. Seráfico P.S. Francisco, provincia de S. Pedro y S. Pablo de Mechoacán en la Nueva España. Zamora (México). El Colegio de Michoacán. 
REGUERA RODRÍGUEZ, A.T. (1998): Geografía de estado: los marcos institucionales de la ordenación del territorio en la España contemporánea (1800-1940). León. Universidad de León.

SILVA SUÁREZ, M. (Ed.) (2005): Técnica e ingeniería en España. III El siglo de las luces. De la industria al ámbito agroforestal. Ensayo introductorio y presentación, 9-46. Zaragoza. Institución Fernando el Católico, Prensas Universitarias. Madrid. Real Academia de Ingeniería.

SKELTON, R. A. (1958): «Cartography», en A History of Technology. Volume IV: The Industrial Revolution (Singer, C; Holmyard, E, Hall, A y Williams, T., Eds.). Oxford, Oxford University Press.

THROWER, N.J.W. (1996): Maps and Civilization: Cartography in Culture and Society. Chicago. University of Chicago Press.

VALCÁRCEL, L. (1940): Revista del Museo Nacional, Vol. 9-10. Lima. Museo Nacional de Perú.

WOOD, D. (1992): The Power of Maps. Nueva York. The Guilford Press. 
